University of Nebraska - Lincoln

DigitalCommons@University of Nebraska - Lincoln

USDA National Wildlife Research Center - Staff

Publications

U.S. Department of Agriculture: Animal and Plant Health Inspection Service

October 2005

\title{
A visual method for indexing muskrat populations
}

Richard M. Engeman

USDA-APHIS-Wildlife Services, s_r100@yahoo.com

Desley A. Whisson

Department of Wildlife, Fish and Conservation Biology, University of California

Follow this and additional works at: https://digitalcommons.unl.edu/icwdm_usdanwrc

Part of the Environmental Sciences Commons

Engeman, Richard M. and Whisson, Desley A., "A visual method for indexing muskrat populations" (2005). USDA National Wildlife Research Center - Staff Publications. 216.

https://digitalcommons.unl.edu/icwdm_usdanwrc/216

This Article is brought to you for free and open access by the U.S. Department of Agriculture: Animal and Plant Health Inspection Service at DigitalCommons@University of Nebraska - Lincoln. It has been accepted for inclusion in USDA National Wildlife Research Center - Staff Publications by an authorized administrator of DigitalCommons@University of Nebraska - Lincoln. 


\title{
A visual method for indexing muskrat populations
}

\author{
Richard M. Engeman ${ }^{\mathrm{a} . *}$, Desley A. Whisson ${ }^{\mathrm{b}}$ \\ ${ }^{a}$ National Wildife Research Center, 4101 Laporte Atemue, Fort Collins, CO 80521-2154, USA \\ ${ }^{b}$ Department of Wildlife, Fish and Consertation Biology, Unirersity of California, One Shields Ate, Datis. CA 95616. CSA
}

\begin{abstract}
The native range for muskrats (Ondatra zibethicus) includes much of North America, but they also have been introduced beyond their native range, including into the Fall River, California, where they have come into conflict with human interests. An easily applied method to assess their abundance is an important need for their management. We developed a muskrat visual index (MVI) to provide the information necessary to address this need. Observations were made at randomly located sites along the river. The number of muskrats observed during a $45 \mathrm{~min}$ period was recorded during the late afternoon peak activity time at each sitc on multiple days. The mean number observed over sites was calculated for each day. The index was the mean of the daily means. These design and measurement methods present valuable advantages over most traditional muskrat indexing methods in this environment. Traditional methods usually involve counting burrows or houses. However, in a relatively stable environment such as along the Fall River, muskat burrows and houses tend to be long-lasting structures, making acute changes in population difficult to detect by these methods. Examining these structures for activity can be time-consuming and labor-intensive. Of particular importance, the statistical properties inherent to the MVI data structure permit calculation of standard errors, confidence intervals and statistical tests allowing quantitative comparisons among MVI values. Development of a management program for muskrats on the Fall River will require understanding of muskrat population fluctuations and densities, as well as knowledge of the effectiveness (short- and long-term) of control strategies. Here we develop a useful method, derive its statistical properties, and present bascline information for managing muskrats along the Fall River.
\end{abstract}

Published by Elsevier Ltd.

\section{Introduction}

A frequent problem in wildife biology is that the population and/or density of the animal of interest can be difficult to accurately assess with current methods, or the economic or logistical costs of doing such an assessment are prohibitive. Besides these issues, the statistical theory used to produce density estimates usually is predicated on assumptions, that when violated result in estimates of questionable quality (see Leidloff (2000) for an excellent examination of potential problems with capture-recapture methods, and Burnham et al. (1980) for a similar discussion on line transect methods). However, density estimates may be unnecessary for research or management purposes, if an index that tracks population changes can provide the information necessary to make management decisions or to evaluate the impact of a control program (Caughley, 1977). To be practical, such an index should be simple and easily applied in the field, while providing sensitivity to reflect population changes.

\footnotetext{
${ }^{*}$ Corresponding author. Tel.: +l-970-266-6091; fax: +1-970266-6089.

E-mail address: richard.m.cngeman@usda.gov (R.M. Engeman).
}

Conflict of muskrat (Ondatra zibethicus) activities with human interests (e.g., Hygnstrom et al., 1994) was the motivating factor for monitoring muskrats along the Fall River. Muskrats are not native to the Fall River, but by the 1930s muskrats that had escaped a fur farm along a tributary had populated the Fall River Valley (Storer, 1937; Shuler, 2000). High muskrat numbers and their burrowing habits have implicated muskrats as a major cause of bank erosion and collapse along the Fall River, as well as several levee breaks (Shuler, 2000). The associated increase in sedimentation of the river and the effect on stream channel morphology may be detrimental to the wild trout fishery and the threatened Shasta crayfish (United States Fish and Wildlife Service, 1997; Shuler, 2000). Assessing the magnitude of the problem and development, implementation, and evaluation of an integrated pest management strategy will require a practical means for monitoring muskrat populations in the Fall River.

Muskrats are probably the most important furbearer in North America, and a variety of procedures have been applied to index muskrat populations. Most common among these have been counting of active houses, usually in winter 
(Thurber et al., 1991; Kroll and Meeks, 1985; Proulx and Gilbert, 1984). Counts of muskrat sign such as feeding platforms, defecation sites, and tracks also have been used as indices of muskrat populations (Thurber et al., 1991). While the ability of muskrats to construct either houses or dig burrows into banks has enabled them to occupy most aquatic habitats throughout North America and Europe (MacArthur and Aleksiuk, 1979; Willner et al., 1980; Dell et al., 1983; Danell, 1978), house counts are most applicable to areas where this is the predominant dwelling for muskrats. Even so, application of house counts requires differentiation between active and inactive houses, as well as differentiation between houses and other structures. However, muskrats appear to prefer to burrow into banks rather than build lodges, unless the population is very dense (Messier and Virgil, 1992). One factor that makes the Fall River so suitable to muskrats is the low variation in water levels. This allows burrows to persist and reduces the necessity for muskrats to build houses for winter. Soper and Payne (1997) suggested that low fluctuation in water levels in marshes in Newfoundland favored building burrows, and Proulx and Gilbert (1984) suggest that winter house counts may not be reliable in areas with stable water levels if muskrats primarily use burrows in summer. Thus, traditional methods for indexing muskrat populations probably are not well-suited for the relatively stable environment along the Fall River, and they also would be unlikely to exhibit the needed sensitivity to reflect acute population changes over a short span of time, such as would be required to assess control efficacy.

Of particular interest to us was the development and application of a low-labor, low-cost index method to track changes in the muskrat population in the Fall River, California. Here, we describe a visual monitoring method we developed for muskrats, along with derivation of its statistical properties and provision of baseline results for the Fall River.

\section{Methods}

\subsection{The Fall River}

The Fall River is part of the Sacramento River Watershed in northeastern Shasta County, California. The river is almost entirely spring fed with base flows from 400 cubic feet per second (cfs) to $1200 \mathrm{cfs}$. The Upper Fall River is a low gradient stream that meanders through a broad, flat flood plain. At a few locations, 3-6-m high levees confine the river, but in general, the confinement is only on one side of the river. The bed of the Fall River is covered with sand deposits, with limited areas of exposed clay, hardpan or volcanic cobbles. Most of the lands alongside the river are privately owned. The principal land use activities are livestock grazing, hay and wild rice production, recreation and residential development (Department of Water Resources, 1998).

\subsection{Sites}

We randomly located 45 sites along the Fall River from the Glenburn Road Bridge to Spring Creek. Sites were separated by a minimum of $100 \mathrm{~m}$. Each site was comprised of a $100 \mathrm{~m}$ long section of river and banks, measured using a Bushnell Yardage Pro 600 rangefinder and included both banks of the river. These sites represented the continuum of habitat types available to muskrats in three segments of the river. Sites 1-11 were located in the lower river segment, from the Tule River confluence downstream. The Tule River confluence is an important demarcation because muskrats which escaped into the Tule River produced in the population in the Fall River. Sites $12-30$ were located in the middle river segment, upstream from the confluence. Observations were taken at sites 1-30 twice during mid-summer (JulyAugust), and twice during late summer/fall (SeptemberOctober). An additional 15 sites were located in the upper segment, upstream from site 30 . Observations were taken at these sites 4 times in late summer/fall.

Ninety percent of muskrat activity occurs at night, with peaks at dusk and dawn (MacArthur, 1980; Brooks, 1985). Stewart and Bider (1977) found bimodal peaks of activity, in late afternoon between 1600 and $1700 \mathrm{~h}$ and after sunset between 2200 and $2300 \mathrm{~h}$. Small home ranges are typical with most activity occurring within a $15-$ to $25-\mathrm{m}$ radius of a "home burrow" (MacArthur, 1978, 1980). Thus, our observations were made during the $4 \mathrm{~h}$ prior to sunset when muskrats were likely to be most active while being easily visible. Observations were made from a small aluminum boat anchored at one end of each site. Each observation point was chosen so all of the site could be easily viewed, and was the same for each of the 4 counts. After a 10-min waiting period at each site, we counted the number of muskrats seen within a $100 \mathrm{~m}$ river segment, delineated as above, during a $45 \mathrm{~min}$ period. Binoculars were only used when necessary to confirm observations. To produce a population index, either the number of muskrat observations or the number of individual muskrats can be used. We chose the former, because the latter is more difficult to measure accurately. Clearly, to insure the comparability of index values, the same measure must be applied at each observation occasion.

\subsection{Index calculations}

We formally define in statistical terms the data structure from which our muskrat visual index (MVI) is calculated. Assume that $s$ sites are observed for muskrats on each of $d$ days. Let $x_{i j}$ represent the number of muskrat observations on the $i$ th site on the $j$ th day. We now write a mixed linear model (e.g., McLean et al., 1991; Wolfinger et al., 1991) to describe the $x_{i j}$ :

$x_{i j}=\mu+S_{i}+D_{j}+e_{i j}$.

The term $\mu$ is the overall mean number of muskrats observed per site per day. $D_{j}$ is a random effect due to the day on 
which an observation was made with $j=1,2,3 \ldots, d$, and $d$ is the number of days the sites are monitored. $S_{i}$ is a random effect due to the $i$ th site with $i=1,2,3, \ldots, s_{j} \leqslant s$ representing the number of sites contributing data on the $j$ th day. We felt it unreasonable to presume that no sites would be rendered unobservable by the elements, or other factors out of the control of the investigator, for each of the $d$ days. Thus, we have allowed the number of sites used in the calculations to differ between days. The $e_{i j}$ represents random error associated with each site each day.

We also avoid biologically unrealistic assumptions concerning the distribution of the random effects prior to calculating the variance of MVI. It is possible that animals could roam distances greater than the separation between observation sites (in our case a minimum separation of $100 \mathrm{~m}$ was incorporated for animals that typically do not move over $30 \mathrm{~m}$ from burrow area). Also, sites that are closer together likely share more physical characteristics than more distantly separated sites. Therefore, we do not consider the number of muskrats observed to be independent across the sites. Similarly, we cannot consider environmental and climatic conditions to be unrelated across days. Hence, we also do not consider the number of muskrats observed on each day to be independent. Only the $e_{i j}$, as random observational noise, are considered independent and identically distributed with mean $=0$ and variance $=\sigma_{e}^{2}$.

The calculation of the MVI can now be written in terms of the $x_{i j}$ as

MVI $=\frac{1}{d} \sum_{j=1}^{d} \frac{1}{s_{j}} \sum_{i-1}^{s_{i}} x_{i j}$

Then the variance of the MVI is

$\operatorname{var}(\mathrm{MVI})=\operatorname{var}\left(\frac{1}{d} \sum_{j=1}^{d} \frac{1}{s_{j}} \sum_{i=1}^{s_{j}} x_{i j}\right)$

which can be equivalently written as

$$
\begin{aligned}
\operatorname{var}(\mathrm{MVI}) & =\frac{1}{d^{2}} \operatorname{cov}\left(\sum_{j=1}^{d} \frac{1}{s_{j}} \sum_{i=1}^{s_{j}} x_{i j}, \sum_{j^{\prime}=1}^{d} \frac{1}{s_{j^{\prime}}} \sum_{i^{\prime}=1}^{s_{j^{\prime}}} x_{i^{\prime} j^{\prime}}\right) \\
& =\frac{1}{d^{2}} \sum_{j=1}^{d} \sum_{j^{\prime}=1}^{d} \frac{1}{s_{j}} \frac{1}{s_{j^{\prime}}} \sum_{i=1}^{s_{j}} \sum_{i^{\prime}=1}^{s_{j^{\prime}}} \operatorname{cov}\left(x_{i j}, x_{i^{\prime} j^{\prime}}\right) .
\end{aligned}
$$

If we let the $\operatorname{var}\left(S_{i}\right)=\sigma_{s}^{2}$ and $\operatorname{var}\left(D_{j}\right)=\sigma_{d}^{2}$, then using the definitions and assumptions given in the subsection on data structure, the covariance structure below follows, with the nonzero elements resulting from the lack of independence among observations:

$$
\begin{gathered}
\operatorname{cov}\left(x_{i j}, x_{i^{\prime} j^{\prime}}\right)=\sigma_{s}^{2}+\sigma_{d}^{2}+\sigma_{e}^{2} \quad \text { if } i=i^{\prime} \text { and } j=j^{\prime}, \\
\sigma_{s}^{2} \quad \text { if } i=i^{\prime} \text { and } j \neq j^{\prime}, \\
\sigma_{d}^{2} \quad \text { if } i \neq i^{\prime} \text { and } j=j^{\prime}, \\
0 \quad \text { if } i \neq i^{\prime} \text { and } j \neq j^{\prime} .
\end{gathered}
$$

Substitution into the quadruple summation of the variance formula produces the following result:

$\operatorname{var}(\mathrm{MVI})=\frac{\sigma_{s}^{2}}{d} \sum_{j=1}^{d} \frac{1}{s_{j}}+\frac{\sigma_{d}^{2}}{d}+\frac{\sigma_{e}^{2}}{d^{2}} \sum_{j=1}^{d} \frac{1}{s_{j}}$

If all $s$ of the sites provide observations each day, then this formula simplifies to

$\operatorname{var}(\mathrm{MVI})_{\text {equal sample size }}=\frac{\sigma_{s}^{2}}{s}+\frac{\sigma_{d}^{2}}{d}+\frac{\sigma_{e}^{2}}{s d}$.

Estimation of $\operatorname{var}(\mathrm{MVI})$ requires variance component estimates for $\sigma_{s}^{2}, \sigma_{d}^{2}, \sigma_{e}^{2}$, which can be produced by applying a program such as SAS PROC VARCOMP (SAS Institute, 1996 ) with a restricted maximum likelihood estimation procedure (REML).

Appendix A presents a subset of our data from this study to demonstrate the calculation of the MVI. Appendix B presents SAS code for calculating the variance components needed in the formula for the MVI variance estimate.

\begin{tabular}{|c|c|}
\hline Category & Definition \\
\hline 0 & No burrows seen \\
\hline 1 & $<1$ burrow entrance/m of river bank \\
\hline 2 & $\begin{array}{l}2-5 \text { burrow entrances } / \mathrm{m} \text { of bank, and along } \\
<50 \% \text { of site }\end{array}$ \\
\hline 3 & $\begin{array}{l}>5 \text { burrow entrances } / \mathrm{m} \text { of bank and along } \\
>50 \% \text { of site. (Banks in this category typ- } \\
\text { ically are riddled with burrows to the extent } \\
\text { that the bank is near collapse, and the ac- } \\
\text { tual number of burrows would be difficult to } \\
\text { count) }\end{array}$ \\
\hline
\end{tabular}

\subsection{House count and burrow indices}

For comparative purposes we also indexed the muskrat structures present at each site. A count of houses was made for each site. The number of burrows was visually indexed categorically according to their density along the banks:

\subsection{Data analyses}

For comparative purposes we were interested in three river segments: the lower river below the Tule River confluence ( sites 1-11), the middle segment above the confluence (sites 12-30), and the upper sites added during the late summer/fall observation period (sites 31-45). We also were interested in population changes in the river segments between the mid-summer and late summer/fall observation periods. Separate MVI and associated statistics were therefore calculated for each river segment in each observation period. Means of the house counts were calculated across sites for each river segment, and river segments were compared using a one-way ANOVA. Because we were most interested in muskrat high-impact areas, we calculated percentages of sites from each river segment with a category 
3 burrow index. Pearson's Chi-square was used to test for differences between segments in percentages of sites in category 3 burrow density. The burrow and house indices were compared qualitatively across river segments with the MVI results using direct observations of muskrat activity ( 3 river segments do not provide adequate information to calculate informative correlations).

\section{Results}

The ordered magnitudes of the MVI, house count and burrow density indices were not in concordance over the three river segments (Table 1). The house count index increased from the lower through upper river segments, whereas the middle river segment had the lowest MVI (in both seasons), followed by the lower and upper segments. The percentage of sites with burrow density in category 3 increased dramatically from the lower river segment to the middle segment $\left(X^{2}=5.79, \mathrm{df}=1, p=0.016\right)$, but the upper was only slightly greater than the middle segment $\left(X^{2}=0.248 \mathrm{df}=\right.$ $1, p=0.62$ ). Differences were not detected in MVI values between the mid-summer and late summer/fall observation periods for either the lower $(z=0.223, p=0.82)$ or middle river $(z=0.150, p=0.88)$ segments. Also, differences were not detected between the lower and middle segments in mid-summer $(z=0.340, p=0.78)$ or late summer/fall $(z=0.642, p=0.52)$. However, the comparison between the middle and upper segments in late summer/fall suggested a potential for difference in muskrat numbers $(z=1.59, p=$ $0.11)$. No differences were detected among the river segments using house counts $(F=0.19, \mathrm{df}=2,42, p=0.83)$.

\section{Discussion}

Counts of durable structures such as muskrat houses and burrows do not offer the ability to readily detect short-term population changes, at least on the Fall River. In more stable environments without severe seasonal changes such constructions would tend to be more permanent. Thus, they would not be particularly useful for examining control efficacy or other acute effects on population. House counts burrow density indices could only be used to make general comparisons between river segments, but without a reference to the applicable time frame in which the construction activity took place. Knowledge of disintegration rates of burrows and houses in the Fall River environment would be needed to evaluate the time frame for which those indices apply. On the other hand, not all muskrat habitats may be amenable to visual counts, such as in some densely vegetated marsh situations or when the water is frozen. The visual observation method presented here should be directly applicable or modifiable to fit situations where sufficient observation visibility exists. The statistical procedures are robust due to the minimal associated assumptions, and they would remain the same even if site layout or visual obscrvation procedures were modified.

We did not find seasonal differences (mid-summer versus late summer/fall) using the MVI, and only marginal evidence that population differences may exist between river segments. However, we did not have a reason to expect that differences would exist. The most important data we obtained were baseline values for monitoring population changes. These data will be especially valuable for assessing efficacy if a control program is initiated along a portion of the Fall River, and if so, for monitoring repopulation of controlled portions. Development of a management program for muskrats on the Fall River should be based on a good understanding of muskrat population fluctuations and densities, as well as knowledge of the effectiveness (short- and long-term) of control strategies.

There are several important points to make relative to the derivation, calculation, and application of the variance formula for the MVI. First, implementation of the MVI defines a data structure that was well described by a linear model structure. This structure led to the derivation of a variance formula with minimal restrictive assumptions about the relationships among observation sites through space and time. Thus, a measure of precision is available each time an index is calculated.

Beyond the derivation of the variance formula, we should point out the importance of using current methods (REML estimation) and software (SAS PROC VARCOMP) for estimating the variance components that are needed in the MVI variance formula. Many "(old) standard" statistical texts (e.g., Snedecor and Cochran, 1989; Sokal and Rohlf, 1995 ) present variance component estimation in the context of method-of-moment estimation from analysis of variance tables. This approach has severe weaknesses (e.g., Searle et al., 1992), including the potential for negative variance component estimates. With current capabilities of personal computers, the more appropriate methods for estimating variance components can be accomplished on the desktop using iterative procedures such as maximum likelihood or the more preferred REML estimation (The text by Searle et al. (1992) is accepted in the statistics community as a "standard" for variance component estimation).

The variance formula allows the quality of a calculated MVI to be assessed on the basis of precision using variance, standard error, and coefficient of variation. The calculation of the variance components used in the variance formula also provide the investigator with useful information for planning future studies, as the relative contributions of site-to-site variation and day-to-day variation can be examined to optimize the combination of days and sites for the next assessment. Conceptually, this approach is similar to that of Link et al. (1994), in the much different context of bird counts, as they examined the effects of variability due to the inexactness of surveying wildlife populations. They concluded that replication of counts within each survey site generally should receive less emphasis than acquiring 
Table 1

The MVI, mean number of houses/site, and the percent of sites with high burrow density ( $>5$ burrow entrances $/ \mathrm{m}$ of bank and along $>50 \%$ of site-category 3 sites) calculated from three segments of the Fall River, CA

\begin{tabular}{|c|c|c|c|c|c|c|c|}
\hline \multirow[t]{2}{*}{ Sites } & \multirow[t]{2}{*}{ Period } & \multirow[b]{2}{*}{ MVI } & \multirow[b]{2}{*}{$\mathrm{SE}$} & \multicolumn{2}{|c|}{ Houses } & \multicolumn{2}{|c|}{$\%$ High burrow density } \\
\hline & & & & $x$ & $\mathrm{SE}$ & $\%$ & $\mathrm{SD}$ \\
\hline Lower & Mid-summer & 0.96 & 0.50 & & & & \\
\hline$(1-11)$ & Latc summer/fall & 1.13 & 0.57 & 0.55 & 0.25 & 12.5 & 11.7 \\
\hline Middle & Mid-summer & 0.77 & 0.24 & & & & \\
\hline$(12-30)$ & Late summer/fall & 0.71 & 0.32 & 0.63 & 0.21 & 63.2 & 11.1 \\
\hline $\begin{array}{l}\text { Upper } \\
(31-45)\end{array}$ & Late summer/fall & 1.23 & 0.08 & 0.87 & 0.54 & 71.4 & 12.1 \\
\hline
\end{tabular}

additional survey sites, although they indicate, as we do, that costs and logistics could be the determining factors in setting up a design. Rather than two, we estimated three sources of variation for the MVI variance formula, and we found days had a greater effect on estimation than sites. Although both sources of variation impacted estimation, if a logistical choice had to be made between adding more days or adding more sites, then the addition of more days should receive greater emphasis.

If the MVI is being used to monitor populations within an area at different times, or among different areas, then statistical comparisons of the MVI would be of interest, especially when looking at topics such as muskrat populations before and after a control program, or populations in river segments with and without control. This is easily accomplished by calculating the MVIs to be compared and their respective variance estimates, followed by the application of the standard $z$-test for comparing means, or equivalently, the Wald statistic (e.g., Mantel, 1987). The $z$-statistic also can be used to calculate confidence intervals for the MVI.

Caughley (1977) demonstrated the difficultics and assumptions one must make to produce a variance estimate when the sampling methodology does not provide the theoretical basis from which a variance can be derived directly. Fortunately, the MVI data structure permits a straightforward variance estimation procedure. If the day and site variance components have been estimated from an earlier application of the MVI, then the number of days and sites required to produce a desired precision for a similar future situation can be estimated by examining the variance formula (equal sample size version) as a response surface question with days and sites as the independent variables and the variance as the dependent variable. Obviously, with two independent variables and one dependent variable no single solution would exist, but might be optimized within the constraints of the experimental resources.

\section{Acknowledgements}

This research was funded by the Fall River Resource Conservation District. We thank D. Marcum (University of California Cooperative Extension, Shasta County) for coordinating the field work, and R. Ruth, J. McCammon, and J. Shuler for collecting data. K. Fagerstone, T. Mathies and M. Pipas provided valuable reviews of this paper.

\section{Appendix A.}

Example data set to demonstrate the statistical calculation methods for the MVI. These data are the number of muskrats observed on 4 days from 15 sites spaced $>100 \mathrm{~m}$ apart along a segment the upper Fall River, California in late summer/fall.

\begin{tabular}{cllll}
\hline Site \# & Day 1 & Day 2 & Day 3 & Day 4 \\
\hline 1 & 1 & 0 & 3 & 1 \\
2 & 1 & 0 & 3 & 0 \\
3 & 1 & 2 & 0 & 0 \\
4 & 3 & 1 & 1 & 0 \\
5 & 2 & 0 & 3 & 3 \\
6 & 0 & 1 & 1 & 1 \\
7 & 1 & 2 & 4 & 5 \\
8 & 0 & 4 & 0 & 2 \\
9 & 0 & 0 & 2 & 6 \\
10 & 0 & 2 & 2 & 1 \\
11 & 0 & 0 & 1 & 1 \\
12 & 0 & 1 & 1 & 0 \\
13 & 0 & 0 & 0 & 0 \\
14 & 2 & 0 & 2 & 2 \\
15 & 4 & 0 & 1 & 0 \\
& & & & \\
Mean & 1.00 & 0.87 & 1.60 & 1.47 \\
\hline
\end{tabular}

$\mathrm{MVI}=(1.00+0.87+1.60+1.47) / 4=1.23$. 


\section{Appendix B.}

SAS code for calculating variance components first using PROC VARCOMP, where the data are contained in a file named MUSKRATS.DAT formatted into 3 columns for site number, day number, and observed number of muskrats.

\section{Code for PROC VARCOMP}

data a;

infile muskrats.dat;

input site day muskrats;

proc varcomp method $=$ reml;

class site day;

model muskrats $=$ site day $/$ fixed $=0$;

run;

\section{References}

Brooks, R.P., 1985. Microenvironments and activity patterns of burrow-dwelling muskrats (Ondatra zihethicus) in rivers. Acta Zoologica Fennica 173, 47-49.

Burnham, K.P., Anderson, D.R., Laake, J.L., 1980. Estimation of Density from Line Transect Sampling of Biological Populations. Wildlife Monographs, Vol. 72, 1-202pp.

Cauglley, G., 1977. Analysis of Vertebrate Populations. Wiley, New York. $254 \mathrm{pp}$.

Danell, K., 1978. Ecology of the Muskrat, LibcrTryck, Stockholm, Sweden.

Dell, D.A., Chabreck, R.H., Linscombe, R.G., 1983. Spring and summer movements of muskrats in a Louisiana coastal marsh. Proccedings of the Annual Conference of the Southeast Association of Fish and Wildlife Agencies, Asheville, North California, Vol. 37, pp. 210-218.

Department of Water Resources (DWR), 1998. Aquatic monitoring and assessment for the Upper Fall River. Draft Report. March, 1998 .

Hygnstrom, S.E., Timm, R.M., Larson, G.E., 1994. Prevention and Control of Wildlife Damage. Univ. Neb. Coop. Exten., US Department of Agriculture, Great Plains Agricultural Council, Washington, DC.

Kroll, R.W., Mecks, R.L., 1985. Muskrat population recovery following habitat re-establishment near southwestern Lake Erie. Wildlife Society Bulletin 13, 483 486 .

Leidloff, A.C., 2000. Habitat utilisation by the grassland melomys (Melomys burtoni) and the swamp rat (Rattus lutrelus) in a coastal heathland of Bribie Island. South-East Queensland. Ph.D. Dissertation, Queensland University of Technology, 147pp.
Link, W.A., Barker, R.J., Sauer, J.R., Droege, S., 1994. Within-site variability in surveys of wildlife populations. Ecology 75, 1097-1108.

MacArthur, R.A., 1978. Winter movements and home range of the muskrat. Canadian Field Naturalist 92, 345 349.

MacArthur, R.A., 1980. Daily and seasonal activity patterns of the muskrat Ondatra zibethicus as revealed by radiotelemetry. Holarctic Ecology $3,1-9$.

MacArthur, R.A., Aleksiuk, M., 1979. Seasonal microenvironments of the muskrat (Ondatra zibethicus) in a northern marsh. Journal of Mammalogy 60, 146-154.

Mantel, N., 1987. Understanding Wald's test for exponential families. The American Statistician 4l, 147-148.

McLean, R.A., Sanders, W.L., Stroup. W.W.. 1991. A unified approach to mixed linear models. The American Statistician 45, 54-64.

Messier, F.. Virgil, J.A., 1992. Differential use of bank burrows and lodges by muskrats. Ondatra zibethicus, in a northern marsh environment. Canadian Journal of Zoology 70, 1180-1184.

Proulx. G., Gilbert, F.F., 1984. Estimating muskrat population trends by house counts. Journal of Wildlife Management 48, 917-922.

SAS Institute, 1996. SAS/STAT User's Guide. SAS Institute, Carey, North Carolina, 1686pp.

Searle, S.R., Casella. G., McCulloch, C.E., 1992. Variance Components. Wiley, New York, 501pp.

Shuler, J., 2000. A history of muskrat problems in northeastern California Proceedings of the 19th Vertcbrate Pest Conference, University of California, Davis in Davis, California, San Diego, California. Vol. 19, pp. $146-153$.

Snedecor, G.W., Cochran, W.G., 1989. Statistical Methods. lowa State University Press, Ames, IA, 507pp.

Sokal, R.R., Rohlf, F.J., 1995. Biometry. Freeman. New York, 859pp.

Soper, L.R., Payne, N.F., 1997. Relationship of introduced mink, an island race of muskrat, and marginal habitat. Annals Zoologica Fennici 34 , $25 t-258$.

Stewart, R.W., Bider, J.R., 1977. Summer activity of muskrats in relation to weather. Journal of Wildlife Management $41,487-499$.

Storer, T.I., 1937. The muskrat as native and alien. Journal of Mammalogy $18,443-460$

Thurber, J.M., Peterson, R.O., Drummer, T.D., 1991. The effect of regulated lake levels on muskrats, Ondatra zibethicus, in Voyageurs National Park, Minnesota, Canadian Field-Naturalist, Vol. 105 pp. $34-40$.

United States Fish and Wildlife Service, 1997. Draft recovery plan for the Shasta crayfish. Pacificus fortis. US Fish and Wildife Servicc. Prepared for Region I, Portland, Oregon, September, 1997.

Willner, G.R., Feldhamer, G.A., Zucker, E.E., Chapman, J.A., 1980 Ondatra =ibethicus. Mammalian Species 141, 1-8.

Wolfinger, R., Tobias, R., Sall, J., 1991. Mixed models: a furure direction. Proceedings of the 16th SAS Users Group Conference (M.J. Rosenberg, Chair), SAS Institute, Carey, North Carolina, New Orleans, Louisiana. Vol. 16, pp. 1380-1388. 